\title{
El trabajo del documentalista y la gestión de la información en los medios de comunicación: nuevos retos y tareas profesionales
}

\author{
Maria de Fátima Garbelini \\ Universidade Federal de Goiás (Brasil)
}

\subsection{Resumen}

Se presenta el papel de los centros de documentación y de los documentalistsa en los medios de comunicación. El documentalista se concibe como gestor coproductor de los programas. Se analiza su perfil profesional. Se reflexiona sobre el caso de Latinoamérica, donde la información transmitida por los medios de comunicación es un agente que reduce la ignorancia de los pueblos y forma ciudadanos. Se propone una mayor integración entre la educación formal del documentalista y del periodista.

Palabras clave: Documentalistas. Medios de comunicación. Funciones. Perfil profesional. Latinoamérica.

\subsection{Abstract}

The role and evolution of mass media documentation centers and their information professional are presented. The information professional is understood as an information manager and program coproducer. Its desirable profile and personal characteristics for the mass media environment are analyzed. The case of Latinoamerica, where the information transmitted by mass media constitutes a key agent in reducing ignorance and educating citizens, is examined. Finally, a greater integration between the degrees in information science and communication science is suggested.

Keywords: Media librarian. Mass media. Roles. Profiles. Latinoamerica.

\section{Introducción}

Sabemos que el Periodismo, por su naturaleza, es la divulgación de los hechos; un trabajo que siempre se desarrolla contrareloj. El periodista es un intermediario de la realidad, que cada día se presenta distinta y que - como dijo recientemente una periodista de Radio Nacional de España— es "precisamente por eso, 
apasionante". Pues bien, consideramos también al documentalista un gestor coproductor de los programas e informaciones en los medios de comunicación, en virtud de la importancia y responsabilidad que implican su trabajo - fundamental en los medios de comunicación - de organización, archivo y apoyo documental e informativo al comunicador para que la información sea divulgada. Ahora bien, es muy importante que el documentalista tenga ciertas cualidades y un perfil profesional adecuado para que su trabajo pueda realmente ser útil al periodista. En particular, las nuevas tecnologías de la información plantean muchos desafíos al funcionamiento de los medios de comunicación. Por todo ello, proponemos una mayor integración en la enseñanza de las carreras de documentalista y periodista para facilitar su trabajo y colaboración en la gestión, producción y divulgación de la información. Esto resulta todavía más importatante, si cabe, en Latinoamérica - un continente muy carente de recursos de documentación y información, al igual que el resto de los países en vías de desarrollo-, en cuyo desarrollo cultural y educativo los medios de comunicación tienen un papel clave.

\section{Nuevos retos y tareas profesionales del documentalista}

El centro de documentación —y el archivo— podría ser considerado como el cerebro de la empresa de comunicación por su función de archivo, apoyo documental y memoria de documentos bibliográficos y audiovisuales. La evolución de los servicios de documentación periodística - y sus implicaciones para el trabajo del documentalista - ha sido trazada por el profesor Bernardino J. Cebrián Enrique, de la Universidad CEU-San Pablo de Valencia, en tres grandes etapas. En la primera etapa — considerada predigital— sólo había un ejemplar impreso de cada fuente. Los profesionales de comunicación se ocupaban del análisis de los documentos. El documentalista tenía que dedicar mucho tiempo al control de la entrada, salida y devolución de los documentos. En la segunda etapa se produjo la digitalización de la producción periodística. Los periodistas empezaron a verse obligados a ir al archivo. El documentalista realizaba búsquedas, convirtiéndose en un intermediario entre las fuentes y el periodista. Finalmente, en la tercera etapa, la actual, los ordenadores de la redacción están conectados al archivo. Los periodistas han empezado también a buscar en la base de datos por sí mismos, son algo más independientes. El documentalista, por su parte, tiene más tiempo para dedicarlo al tratamiento de la información y documentación. A lo largo de esta evolución, se aprecia la gran responsabilidad del documentalista en su tarea de organizar, archivar y apoyar al periodista en su trabajo. Se observa también que el comportamiento del usuario de los documentos audiovisuales es muy distinto de aquél que solamente trabaja con documentos bibliográficos. Por ello, la colección bibliográfica de un centro de documentación de un medio de comunicación tiene características diferentes a las de una biblioteca convencional. Hay que tener todo tipo de fuentes:

Scire. $8: 2$ (jul.-dic. 2002) 153-158. 
desde revistas del corazón a horóscopos, de fútbol, etc. El ritmo de trabajo también es distinto, ya que se trabaja también por la noche, en fines de semana, festivos... A veces parece muy estresante, porque las solicitudes muchas veces son "para ayer... e incluso para anteayer". La indización de fotos o de imagenes también es distinta porque puede tener que reflejar sentimientos como melancolía, tristeza, etc. Hay que recordar que a veces una imagen vale más que mil palabras. Otro factor que consideramos muy importante es que el documentalista ha de estar actualizado con respecto a los personajes políticos, actores, deportistas y otros, para poder identificarlos correctamente o realizar búsquedas sobre ellos. En muchos medios de comunicación actualmente el documentalista participa incluso de las reuniones diarias de las redacciones, asumiendo una mayor responsabilidad en el apoyo al trabajo del periodista. En definitiva, se puede considerar que actualmente hay en los medios de comunicación una mayor conciencia del trabajo del documentalista.

En cuanto a la organización y archivo de documentos, el documentalista debe buscar nuevas técnicas y adaptar lo que aprendió en su Licenciatura de Documentación, porque las técnicas audiovisuales de archivo y búsqueda suelen ser distintas en los medios de comunicación. El trabajo que se desarrolla en un centro de documentación es - y pensamos que debe ser - siempre interdisciplinar. Hemos de trabajar con los propios periodistas, con historiadores y otros especialistas para que identificar e indizar bien la documentación. La responsabilidad del documentalista al archivar y entregar documentos o informar al periodista es muy grande, porque dicha información será divulgada. Muchas veces, como el periodista tiene muy poco tiempo para su trabajo, lo que el centro de documentación le envía se convertirá en su material de soporte para una noticia o programa. Por esto constatamos que el documentalista también participa como gestor de la información. Antes de entrevistar a un personaje, el periodista necesita de las informaciones sobre su vida, fotografías, imágenes etc. Dichos datos deben ser fiables y exactos, y de ellos depende la calidad de la noticia. No debemos olvidar que está en juego la propia credibilidad de la empresa de comunicación.

\section{Desafíos y perfil profesional del documentalista}

La situación actual de la documentación en los medios de comunicación ha cambiado mucho con la Word Wide Web y con todas las tecnologías de digitalización de textos, imágenes, sonido y fotografía. En este nuevo escenario digital, Codina (2000, p. 33) considera al centro de documentación como un núcleo del sistema redaccional y, como consecuencia, una factoría unificada desde donde las noticias se distribuyen a través de los diversos soportes de la empresa informativa y de la página web. Así, se puede llegar a la conclusión de que una empresa de comunicación necesita actualmente de un único centro de documentación que permita y facilite la realización centralizada del trabajo. Sin embargo, en la gran mayo-

Scire. 8 : 2 (jul.-dic. 2002) 153-158. 
ría de las empresas existe todavía un centro de documentación diferente para cada medio.

En este contexto, se plantean al documentalista retos diversos, tanto de carácter general como específico. Entre los primeros, destacan la transición del medio impreso al medio electrónico en el archivo de información, la creciente competitividad y exigencia de rentabilidad y las nuevas tendencias en la organización del trabajo. Otros desafíos más específicos que el documentalista afronta en su trabajo en los medios de comunicación son la enormidad de la información disponible, el elevado número de fuentes de información, la diversidad de tecnologías de tratamiento documental existentes, y la necesidad de mantener una conciencia del valor de la memoria y acceso universal a la información.

Entre las cualidades del documentalista que son importantes para el trabajo en los medios de comunicación destacan las siguientes: cultura general, conocimiento de otros idiomas, gran capacidad de síntesis y objetividad, capacidad de trabajo en equipo, mucha rapidez y agilidad en atender al usuario, expertitud en la búsqueda documental (bibliográfica y automatizada), y habilidad en el tratamiento de la documentación audiovisual. Dado que actualmente hay mucha información disponible, el documentalista tiene que dedicar tiempo a la evaluación y selección de las fuentes de información, porque hoy el profesional de la comunicación está más abierto al trabajo del documentalista, pero es más exigente, quizás porque el trabajo del documentalista en los medios de comunicación está mas definido. Sin embargo, desgraciadamente, todavía son muchas las empresas de comunicación que no conocen o no tienen claros los servicios que el profesional de la documentación puede ofrecerles. Su figura se asocia aún demasiado con la Biblioteconomía; es decir, se tiene la idea, errónea, de que este profesional solamente trabaja con libros y material bibliográfico.

\section{Experiencia Latinoamericana y Brasil}

Como sabemos, los medios de comunicación tienen un papel decisivo en la formación cultural de una población. Especialmente en Latinoamérica — donde muchos países se consideran en vías de desarrollo-, los medios de comunicación ejercen también una función educativa. En estos países los índices de analfabetismo y evasión escolar son muy elevados, porque muchos niños trabajan para ayudar a sus familias a sobrevivir. En el caso de Brasil con una población de 171.320.069 habitantes, 30 millones son analfabetos. Sin embargo, en la mayoría de los hogares hay radio y televisión, y una gran mayoría de jóvenes ven la televisión una media de seis horas diarias. Así pues, los medios de comunicación pueden ser grandes colaboradores en la formación de los ciudadanos latinoamericanos. Puede considerarse también que poseen una gran función integradora, constituyendo un instrumento de la mayor importancia para la democratización

Scire. $8: 2$ (jul.-dic. 2002) 153-158. 
de la información y en la reducción de las desigualdades en el acceso al conocimiento. En Brasil hay también una gran cantidad de cadenas por subscripción, en las cuales podemos considerar que, en cierta manera, la información constituye una mercancía. Sin embargo, es negativo que una gran parte de la población no pueda acceder a estas informaciones por su elevado costo.

No se puede olvidar que el trabajo periodístico debe ser también una actividad de utilidad pública. En este sentido, su principal función debe ser informar para transformar. Desgraciadamente, hay muchos grupos de empresarios del sector de la comunicación en Latinoamérica y Brasil que están manipulando la información: "En la búsqueda del entretenimiento, la función de los medios de comunicación a veces distrae a las personas de la vida real, de sus disgustos, de la verdadera economía, política y de la sociedad, dando la impresión de que lo más importante es no hacer pensar" (Ferreira, 1995). Por otra parte, algunos medios de comunicación en Brasil se están esforzando mucho en colaborar en la formación y la democratización de la información. Como ejemplos, podemos citar la Radio y TV Educativa. Sus programas son muy educativos. Dedican una gran parte de la programación a divulgar información política, geográfica, cultural, económica, matemáticas, lenguas, etc. Muchos de los programas se hacen con un lenguaje de fácil compresión para las muchas personas que no han tenido la oportunidad de estudiar en una escuela. Así pues, consideramos que el trabajo del documentalista en los medios de comunicación en Latinoamérica y Brasil, tiene una función también social, pues debe organizar y archivar documentos y informaciones que muchas veces tienen sobre todo carácter educativo. Además, el documentalista colabora también con el periodista en la elaboración de programas informativos y educativos con el objetivo de reducir cada vez más la ignorancia y falta de conocimientos en estos países con tantos problemas sociales y económicos.

\section{Conclusiones}

Como vimos, el trabajo del documentalista tiene una gran importancia en la gestión de la información en los medios de comunicación. Hay un gran mercado de trabajo en los medios de comunicación para el documentalista que, desgraciadamente, está ocupado por otras carreras profesionales.

Lo que constatamos y la experiencia nos ha podido enseñar, es que el trabajo de organización, archivo y recuperación de los documentos y informaciones en los medios de comunicación puede y debe ser desarrollado por un equipo interdisciplinar de profesionales de las áreas de Periodismo, Documentación, Informática, Historia, etc. Con una dedicación, integración y interés por el trabajo periodístico por parte del documentalista, las informaciones divulgadas tendrán, sin duda, más credibilidad y veracidad para los ciudadanos de cualquier parte del mundo. En la carrera del profesional de comunicación deberían estudiarse y aprenderse también

Scire. 8 : 2 (jul.-dic. 2002) 153-158. 
las técnicas de búsqueda de documentos, junto con más conocimientos de los servicios documentales y de fuentes de información.

Por otro lado, en la carrera del documentalista debería ampliarse la enseñanza del tratamiento de los soportes audiovisuales y de las posibilides y especificidades del trabajo documental en los medios de comunicación.

En definitiva, pensamos que para una mayor integración de los trabajos del documentalista y del periodista merece la pena reflexionar sobre la idea del profesor Bernardino J. Cebrián Enrique, que afirma: "los periodistas tienen que reconocer que necesitan documentar la información. Los profesionales de Documentación tienen que acercarse más a los periodistas, e incluso pensar y actuar como ellos."

\section{Bibliografía}

Bajñon, María Teresa Fernández (1998). La profesión de documentalista: apuntes para una reflexión. // Formación Bibliotecaria, 3, 10, 17 de marzo y 14 de abril de 1998, Madrid. 295-307.

Barros Filho, Clóvis (1995). Ética na comunicação: a informação ao receptor. São Paulo: Moderna, 1995.

Caldera, Jorge; Zapico, Felipe (2001). Principales fuentes de información audiovisual en las televisiones estatales. // Anales de Documentación. 4 (2001) 39-50.

Cebrián Enrique, Bernardino J. (1998). Nuevos enfoques sobre la misión del documentalista en los medios de comunicación.// Documentación de las Ciencias de la Información. 21 (1998) 91-100.

Codina, Lluis. (2000). La documentación en los medios de comunicación: situación actual y perspectivas de futuro. // I Congreso Universitario de Ciencias de la Documentación. Noviembre 2000. Madrid: Universidad Complutense de Madrid. 23-40.

Correia Neto, Alarico (1995). O bibliotecário é um comunicador? // Revista INTERCOM, São Paulo. (1995) 27-38.

Ferreira, Maria Nazareth. (1995). A comunicação (des) integradora na América Latina. São Paulo: EDICON, 1995.

López Yepes, Alfonso (1993). Los nuevos métodos de rastreo sobre textos completos en la documentación automatizada, aplicados a la investigación periodística. // Cuadernos de Documentación. 2 ( junio 1993) 79-100.

Melo, José Marques de (1994). Comunicação de massa y leitura. // APB. São Paulo. 1 (1994) 30-41.

Smit, Johanna W. (1987). Análise documentária: a analise da sintese. Brasília: IBICT, 1987. 